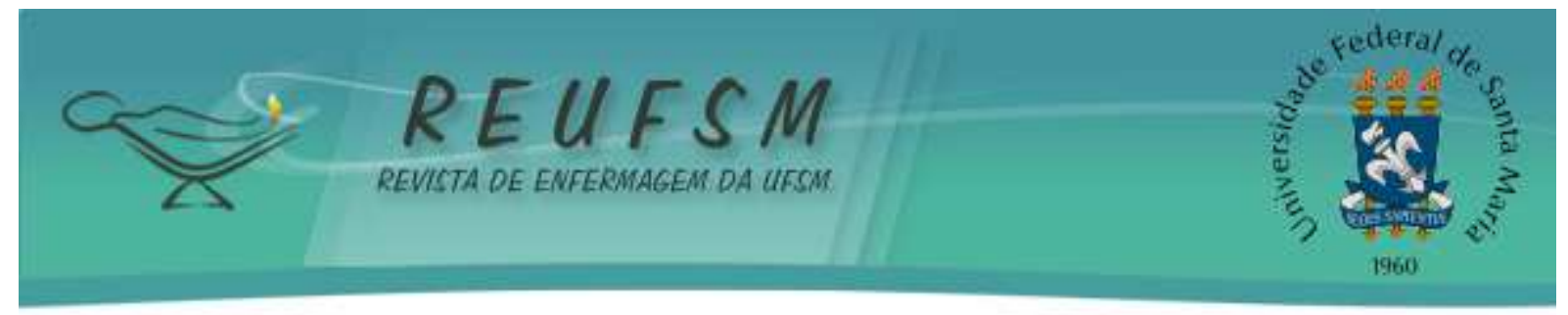

\title{
“A 'DIETA' É TEMPO DE CUIDADOS”: PRÁTICAS DE AUTOATENÇÃO NO PUERPÉRIO NO CENÁRIO RURAL
}

\section{“THE 'DIET' IS A TIME TO CARE”' SELF-CARE PRACTICES DURING THE PUERPERIUM IN THE RURAL ENVIRONMENT \\ “LA 'DIETA' ES TIEMPO DE CUIDADOS”: PRÁCTICAS DE AUTOATENCIÓN EN EL PUERPERIO EN EL ESCENARIO RURAL}

\author{
Isabel Cristina Van der Sand ${ }^{1}$ \\ Lúcia Beatriz Ressel ${ }^{2}$ \\ Marisa Monticelli ${ }^{3}$ \\ Ivis Emília de Oliveira Souza ${ }^{4}$ \\ Janine Schirmer ${ }^{5}$
}

Doi: 10.5902/2179769229045

RESUMO: Objetivos: conhecer os significados das práticas de autoatenção de mulheres, residentes no campo, relativas ao puerpério; identificar as interfaces dessas práticas com os diferentes modelos de atenção à saúde. Método: etnografia desenvolvida em três comunidades rurais de pequeno município do Norte do Rio Grande do Sul/Brasil. Participaram 17 informantes. Na coleta de dados, utilizaram-se técnicas de ObservaçãoParticipação-Reflexão e entrevistas etnográficas. No processo analítico, utilizou-se a proposta de análise temática. Resultados: constatou-se que o puerpério apresenta-se marcado por práticas de autoatenção referentes à alimentação, atividade física, higiene e à sociabilidade produzidas no seio da família/comunidade, com pouca articulação ao setor profissional de cuidados. Conclusão: essas práticas buscam proteger as mulheres-puérperas que, na interpretação de seu grupo social, estão em estado liminar - entre a saúde e a doença. Concomitantemente a isso, conferem poder relativo às puérperas e suas famílias.

Descritores: Enfermagem; Período pós-parto; População rural; Cultura

ABSTRACT: Aims: to discover the meanings of the self-care practices of women living in rural areas regarding the puerperium; to identify the interfaces of these practices with the different models of health care. Method: ethnography conducted in three small city rural communities in the North of Rio Grande do Sul/Brazil. Seventeen participants were involved. Observation-Participation-Reflection techniques and ethnographic interviews were employed in the data collection. In the analytical process, a thematic analysis proposal was used. Results: it was verified that the puerperium is marked by self-care practices related to food, physical activity, hygiene, and sociability arising from the family/community, with little connection with the professional healthcare sector. Conclusion: these practices are intended

\footnotetext{
${ }^{1}$ Enfermeira. Doutora em Ciências. Universidade Federal de Santa Maria. Palmeira das Missões, RS, Brasil. Email: isabelvan@gmail.com

${ }^{2}$ Enfermeira. Doutora em Ciências. Universidade Federal de Santa Maria. Santa Maria, RS, Brasil, E-mail: luciaressel@gmail.com

${ }^{3}$ Enfermeira. Doutora em Enfermagem. Universidade Federal de Santa Catarina. Florianópolis, SC, Brasil. Email: marisamonticelli123@gmail.com

${ }^{4}$ Enfermeira. Doutora em Enfermagem. Universidade Federal do Rio de Janeiro, RJ, Brasil. E-mail: ivis@ superig.com.br

${ }^{5}$ Enfermeira. Doutora em Enfermagem. Universidade Federal de São Paulo. São Paulo, SP, Brasil. E-mail: schirmer.janine@unifesp.br
} 


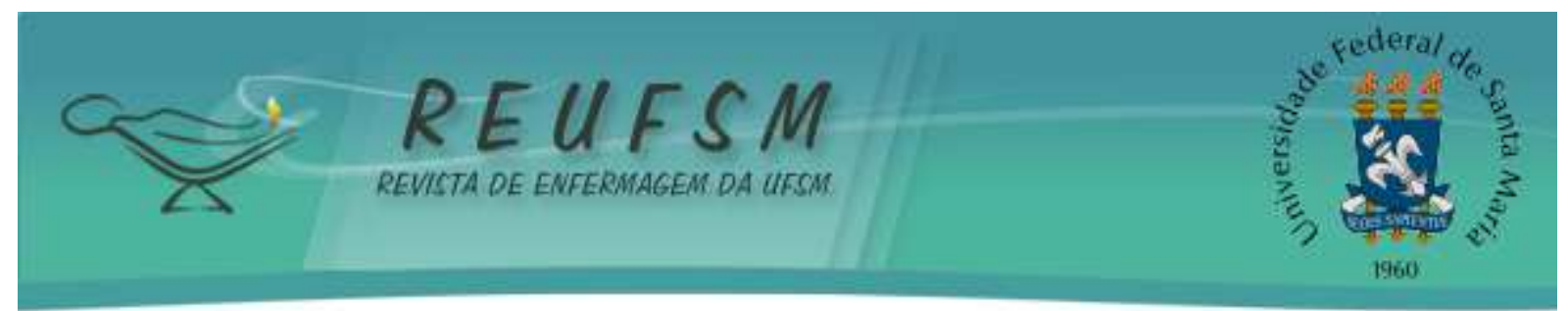

to protect the women who just gave birth, who, in their social group's interpretation, are in a liminal state between health and sickness. Simultaneously, they also grant considerable power to the postnatal women and their families.

Descriptores: Nursing; Postpartum period; Rural population; Culture.

RESUMEN: Objetivos: conocer los significados de las prácticas de autoatención de mujeres, residentes en el campo, relacionadas al puerperio; identificar las interacciones de esas prácticas con los distintos modelos de atención a la salud. Método: etnografía desarrollada en tres comunidades rurales, de un pequeño municipio del Norte del estado del Rio Grande do Sul/Brasil. Participaron 17 informantes. Para la recolección de los datos fueron utilizadas técnicas de Observación-Participación-Reflexión y encuestas etnográficas. En el proceso analítico se utilizó la propuesta del análisis temático. Resultados: se constató que el puerperio se presenta marcado por prácticas de autoatención referentes a la alimentación, actividad física, higiene y a la sociabilidad producida en el ambiente interno a la familia/comunidad, con poca articulación con el sector profesional de cuidados Conclusión: esas prácticas buscan proteger las mujeres puérperas que, en la interpretación de su grupo social, están en estado liminar - entre la salud y la enfermedad. Concomitante a eso, se determina poder a las puérperas y sus familias.

Descriptores: Enfermería, Período pos-parto; Población rural. Cultura

\section{INTRODUÇÃO}

Este estudo trata dos significados culturais das práticas de autoatenção desenvolvidas no puerpério por mulheres do campo, compreendendo que essa etapa faz parte do processo do nascimento (PN). A relação entre o puerpério e o PN justifica-se no entendimento de que este, da mesma forma que não se inicia na concepção, não termina ao se dar à luz a um filho. O PN inicia-se na socialização dos sujeitos, quando as crianças, ao brincarem, desempenham os papéis de mãe e de pai; é algo que passa, também, pela gestação que vai, por meio da transformação de cada membro da família, modificando papéis e identidades; refere-se ao parto e se estende para além dele, passando pelo puerpério. ${ }^{1}$ Trata-se de um processo com características rituais, inserido em determinada cultura, que antecede a gravidez e ultrapassa o puerpério.

Esse nem sempre coincide conceitual e temporalmente com a concepção biomédica, que o define como a etapa em que as modificações do organismo da mulher, provocadas pela gravidez e parto, retornam ao seu estado pré-gravídico, tendo seu início após o parto com a dequitação placentária e término variável, uma vez que se relaciona com o processo de amamentação. ${ }^{2}$

O puerpério, conhecido popularmente no Brasil como "resguardo", "quarentena", "dieta", associa-se com questões atinentes à cultura, ${ }^{3-4}$ entendida como uma rede de 


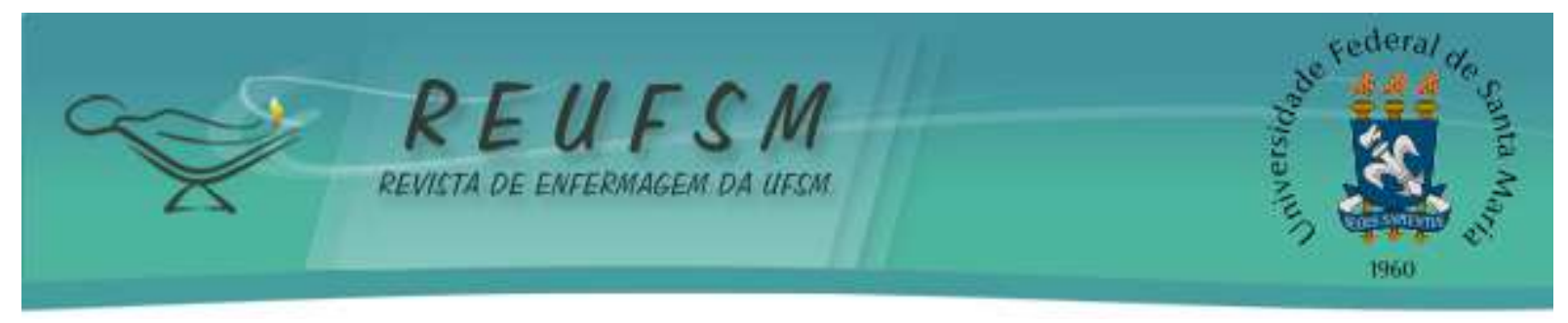

significados, contidos em sistemas simbólicos e estabelecidos socialmente, nos termos do que as pessoas se comportam, interpretam as experiências e guiam suas ações. ${ }^{5}$ Por isso, nesse período modulam-se práticas com a finalidade de proteger a mulher que se encontra, em muitos grupos culturais, num estado liminar e, até mesmo, com risco de morte, ou seja, entre a saúde e a doença e/ou representando perigo para si e para os demais com quem convive..$^{3-4}$

Nessa perspectiva, essas práticas podem ser entendidas como de autoatenção, ou seja, como significados e estratégias que a população utiliza em nível do sujeito e do grupo social para, na intencionalidade de proteção, diagnosticar, explicar, atender, controlar, aliviar, suportar, curar, solucionar ou prevenir os processos que afetam sua saúde, em termos reais ou imaginários, sem a intervenção direta e intencional de curadores profissionais, mesmo quando estes possam ser referência para essa atividade. ${ }^{6}$

Ressalta-se que, apesar da existência de estudos nacionais ${ }^{3-5}$ e internacionais ${ }^{7-9}$ na área da saúde reprodutiva sob a perspectiva cultural, alguns dos quais abordam o puerpério, são escassas as investigações envolvendo mulheres brasileiras campesinas que tratem dessa temática e com essa abordagem. Por isso, e pelo fato de que uma das autoras desta investigação exerce suas atividades profissionais em região do Rio Grande do Sul (RS) que tem características de ruralidade, percebeu-se a pertinência do desenvolvimento de pesquisa envolvendo população rural. Por esses motivos, o presente estudo norteia-se pelas seguintes questões: "Quais os significados das práticas de autoatenção produzidas no puerpério por mulheres do campo? Como essas práticas relativas ao puerpério interagem com os modelos de atenção à saúde?” Assim, seus objetivos são: conhecer os significados das práticas de autoatenção de mulheres residentes no campo relativas ao puerpério; identificar as interfaces dessas práticas com os diferentes modelos de atenção à saúde.

Diante desses objetivos, como referencial teórico, optou-se pelos aportes da antropologia da saúde em sua vertente crítica, representada por Eduardo Menéndez Spina. ${ }^{6,10}$ Reportando-se ao contexto latino-americano, este autor defende a existência de uma pluralidade de modelos de atenção à saúde, interconectados e utilizados pela população de forma simultânea ou sequencial ao longo do tempo, articulados pela autoatenção. ${ }^{6,10}$ Destaca que cada modo de atenção não representa configuração estática e isolada em si mesmo, porque há um processo dinâmico entre as atividades originadas em cada um deles. Visto que as distintas formas de atenção não funcionam sempre de forma excludente, o autor assinala 


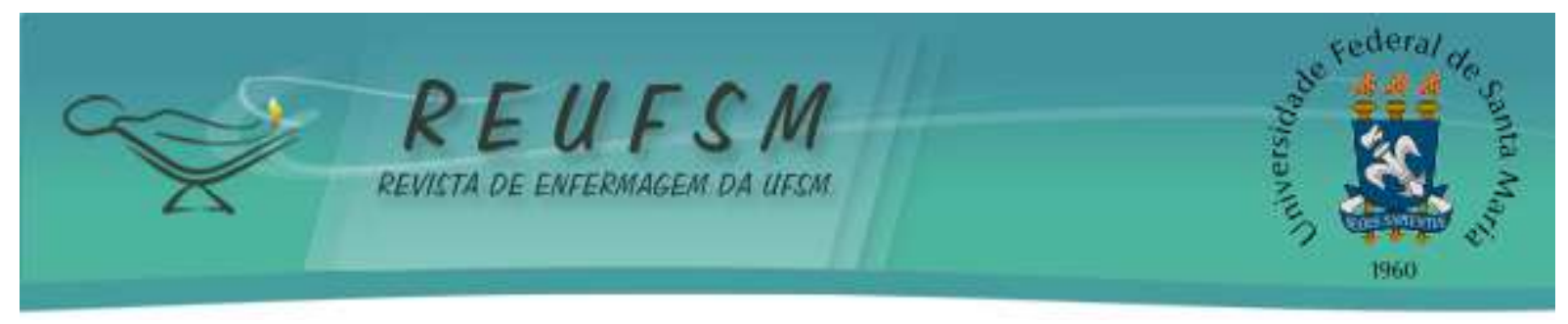

que pode haver interação entre dois ou mais modos de atenção em dois níveis. A interação no primeiro nível se dá quando a iniciativa de integração provém dos setores de atenção que contêm os especialistas, a exemplo de situações em que o Modelo Médico Hegemônico (MMH), cujo paradigma é o biomédico, se apoia, por exemplo, nos grupos de autoajuda como parte do seu plano terapêutico. No segundo nível, a iniciativa parte do próprio sujeito ou do grupo social que padece de algum problema que atinge ou ameaça sua saúde. ${ }^{6}$

O processo de saúde-doença-atenção ancora-se na dialética sujeito-estrutura e nas relações de hegemonia/subalternidade entre os modelos de atenção, em especial MMH e o Modelo de Autoatenção. ${ }^{10}$ Este, cuja definição já foi mencionada, pode se realizar em dois sentidos: o amplo e o restrito. No sentido amplo objetiva a garantia da reprodução biossocial em nível dos microgrupos, especialmente o doméstico, operada a partir de objetivos e de normas da própria cultura. No sentido restrito visa o enfrentamento de agravos à saúde. ${ }^{10}$

\section{MÉTODO}

Estudo etnográfico, desenvolvido entre agosto de 2012 e janeiro de 2014, em município do Norte do RS de 4.098 habitantes, dos quais, à época, 63,7\% eram domiciliados no campo. Dentre estes, 1.248 eram mulheres, das quais 1.179 tinham de dez até 70 anos ou mais. ${ }^{11}$

O cenário focalizado do estudo constituiu-se dos locais em que acontecem as práticas de autoatenção ao nascimento, dentre elas as de puerpério: três comunidades em que viviam as informantes-chave e o Centro Municipal de Saúde, ambiente de atenção à saúde dessas mulheres. O município tinha 100\% de cobertura de Estratégia de Saúde da Família (ESF), com duas equipes alocadas na mesma área física e em zona urbana. A atenção no pós-parto se dava por meio de consulta médica, centrada no recém-nascido.

A definição das informantes-chave (mulheres que desejavam participar do estudo e dominavam o tema da investigação) ${ }^{12}$ deu-se no processo etnográfico, e não a priori. A troca simétrica de saberes entre pesquisadora e informantes permitiu perceber que algumas dominavam mais a temática investigada e, por isso, poderiam ser as informantes-chave. Contudo, a seleção destas guiou-se, ainda, pelos seguintes critérios: 1) estarem vivenciando o PN (gravidez ou puerpério) ou serem pessoas significativas para essas mulheres, ou, ainda, 


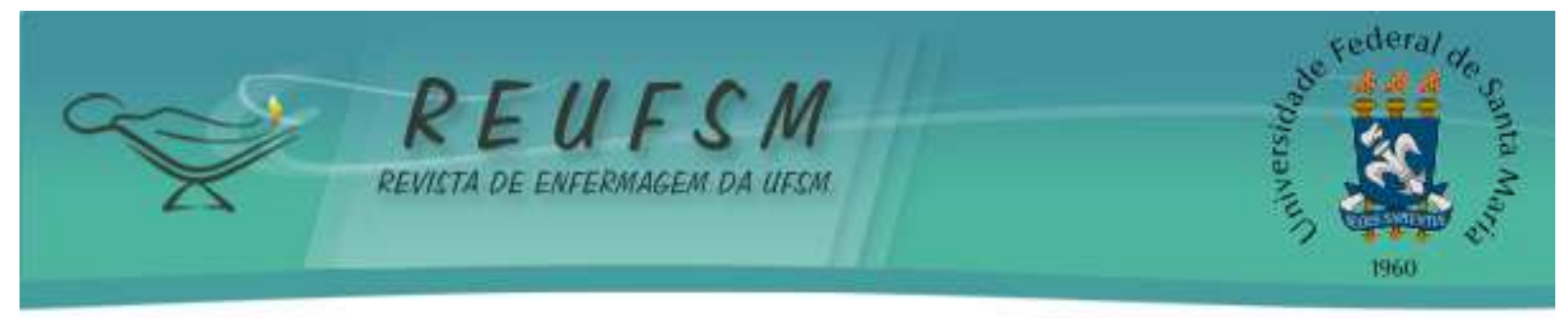

serem mulheres que já tivessem vivenciado o PN em algum momento anterior da vida. 2) essas deveriam residir em uma das três localidades rurais elencadas para a investigação.

A decisão por mulheres vivenciando o PN, e não somente aquelas que já haviam vivenciado, orientou-se pelo valor que as práticas sociais têm na produção da etnografia, visto que sem elas o pesquisador corre o risco de basear-se no que os informantes dizem que fazem e não no que realmente fazem. ${ }^{10}$ A noção de que as práticas de autoatenção são relacionais ${ }^{6,10}$ reforçou a necessidade do uso de alguma técnica de observação, o que só ocorreria se algumas informantes-chave estivessem vivenciando o PN. Por meio das perspectivas e dos fazeres dos diferentes atores significativos na cena do PN, foi possível detectar a gama de articulações entre os modos de atenção operados no enfrentamento das situações vividas no PN, o que incluiu o puerpério. ${ }^{10}$ Tudo isso justificou a inclusão de pessoas significativas de gestantes e puérperas como informantes.

O estudo contou com um total de 17 informantes: dez informantes-chave e sete gerais. Das informantes-chave, duas estavam grávidas, duas em puerpério, três eram pessoas significativas e três eram mulheres que já haviam vivenciado o PN (mãe, avó e trisavó). Como informantes gerais (os que têm ideias genéricas acerca da temática) ${ }^{12}$ foram incluídos parentes, vizinhos das informantes-chave e profissionais das equipes de ESF, representantes do $\mathrm{MMH}$.

Como técnica principal de coleta de dados optou-se pelo modelo ObservaçãoParticipação-Reflexão (O-P-R). ${ }^{12}$ Nas duas primeiras fases do modelo O-P-R, a pesquisadora não permaneceu no campo de forma contínua, mas para operacionalizar a $3^{\mathrm{a}}$ e $4^{\mathrm{a}}$ fases, alternando os dias em que permanecia no cenário (de dois a três dias semanais, inclusive em finais de semana), passou a "pernoitar" com uma das informantes-chave, a seu convite, o que se deu por nove meses seguidos. A partir daí, a pesquisadora participou de atividades no cenário doméstico (rodas de chimarrão, orações, chás, atividades da casa, compras em supermercado, aniversários) e na coletividade (reuniões políticas, atividades de educação em saúde, eventos religiosos), convivendo com os informantes gerais e, mais estreitamente, com informantes-chave. Estas foram acompanhadas nas consultas de pré-natal e em grupo de gestantes, na atenção ao parto e no retorno para casa, destacando-se que na época não havia, nas ESF, consultas de puerpério. 


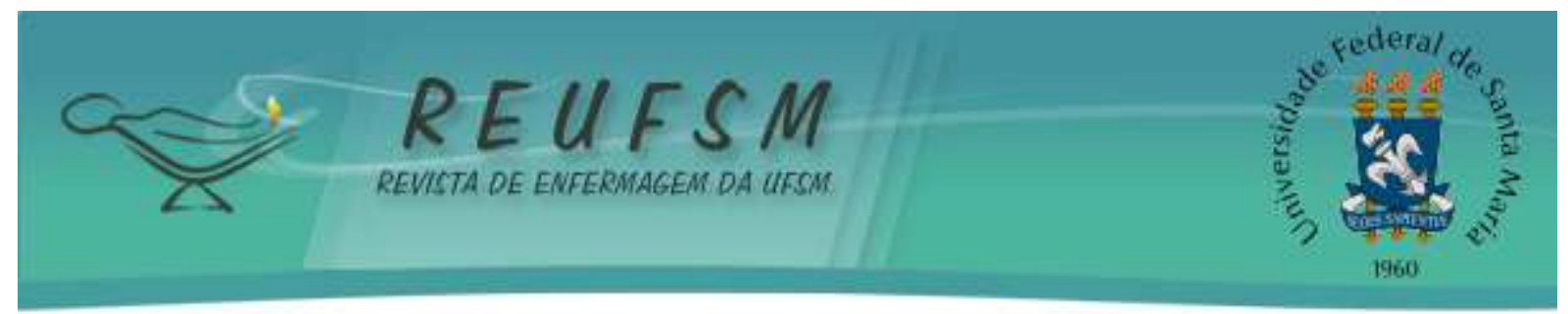

A O-P-R foi complementada pela entrevista etnográfica. Para aquelas que foram se configurando como informantes-chave fez-se, pelo menos, três entrevistas. Na primeira, solicitou-se que contassem um pouco de si, a fim de que se acostumassem com a entrevista gravada em áudio. A segunda orientou-se pela seguinte provocação: "conte-me sobre tua(s) vivência(s) de gravidez, desde que você começou a pensar em engravidar ou suspeitou que estava grávida, até os dias de hoje que você já tem teu(teus) filho(s)". A terceira representou uma oportunidade para a retomada e aprofundamento de questões que surgiram no processo O-P-R, constituindo-se de perguntas pontuais, a exemplo de: "Morena, quando eu estive aqui na tua casa, na semana passada [20 dias de pós-parto], percebi que você não tomou chimarrão. Isso se deve a algo em especial?" Algumas informantes-gerais foram entrevistadas para aprofundar temáticas emergentes da O-P-R e/ou das entrevistas às informantes-chave. Fez-se uso de diário de campo.

A análise temática ${ }^{12-13}$ orientou o processo analítico pelas etapas de: 1) coleta e descrição dos dados brutos, quando foram registradas as informações obtidas pelas técnicas de coleta de dados, procurando, de modo preliminar, identificar os símbolos e os significados contextuais relacionados aos fenômenos em estudo, o que foi feito a partir do foco emic (ponto de vista dos informantes, ou seja, os construtos internos da cultura do grupo) e da dimensão etic do estudo (usando as lentes do referencial teórico adotado); ${ }^{12}$ 2) identificação e caracterização de descritores e componentes, quando, a partir de similaridades e diferenças entre as informações obtidas e seus significados, se buscou descritores emic e etic; 3) análise contextual e de padrões recorrentes, quando se examinaram os dados na busca de ideias saturadas e padrões recorrentes de significados, similares ou diferentes, centrando-se em expressões, formas estruturais ou explanações relacionadas ao domínio da investigação, validando-se os resultados com as informantes; e 4) identificação de temas relevantes e de formulações teóricas, correspondendo à fase mais elevada da análise.

Cabe a ressalva que, para apreender os padrões culturais que informam e justificam as práticas de autoatenção tecidas no puerpério pelas mulheres do campo e as suas interfaces com os modelos de atenção à saúde, considerou-se que a produção dessas práticas, articuladas aos seus significados e sentidos, modula-se por diferentes realidades - social per se, simbólica e clínica - a que estão sujeitas as mulheres participantes do estudo. ${ }^{14}$ 


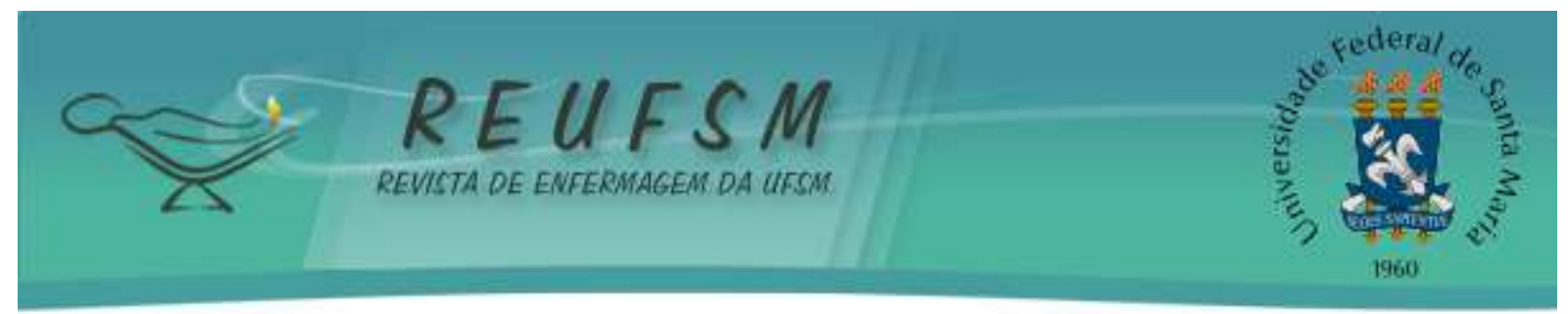

Dentre os critérios de rigor recomendados para a etnoenfermagem e adotados nesta pesquisa, destaca-se a validação dos achados que se deu por meio da confirmabilidade, ou seja, por meio de vários encontros da pesquisadora principal com os informantes, a fim de reafirmar o que ouviu, viu ou experimentou em relação aos fenômenos investigados. Desse modo, no processo de coleta de dados buscou-se checar as interpretações operadas nesse ínterim, em uma espécie de "micro-validações". Em determinado momento, o relatório parcial de pesquisa foi levado para cada informante-chave, a fim de que confirmassem os padrões recorrentes e possíveis temas apreendidos. O relatório final foi lido por três informanteschave, buscando-se a confirmabilidade dos achados. ${ }^{12}$

O projeto de pesquisa foi aprovado pelo Comitê de Ética em Pesquisa da Universidade Federal de São Paulo, sob Parecer Consubstanciado 81600, em 24 de agosto de 2012. Cumprindo os preceitos éticos da Resolução n. 196/96, ${ }^{15}$ vigente à época da coleta dos dados, as informantes-chave assinaram Termo de Consentimento Livre e Esclarecido (TCLE). Aos informantes gerais que foram somente observados, foi solicitada permissão verbal para fazêlo, e aos que foram entrevistados, solicitou-se, também, a assinatura do TCLE.

\section{RESULTADOS}

Do processo analítico emergiu o tema "A 'dieta' é um tempo de cuidados”, originado de cinco padrões culturais: 1) Na "dieta" os alimentos quentes são aconselháveis, e os ácidos, pesados e frios, não; 2) $\mathrm{Na}$ "dieta" a mulher não deve se expor a diferenças ambientais de temperatura; 3) $\mathrm{Na}$ "dieta" a mulher não deve fazer esforço físico; 4) $\mathrm{Na}$ "dieta" a mulher deve ter cuidados em relação à lavagem do cabelo; 5) Os familiares e a comunidade se mobilizam para ajudar e acolher a puérpera na "dieta".

A fim de caracterizar as informantes-chave, destaca-se que a idade média dessas mulheres era de 43,6 anos (mínimo de 22 e máximo de 75 anos). Uma delas era viúva e as demais casadas.

Dentre as principais preocupações do grupo cultural estudado, no puerpério, estão as referentes à alimentação, o que, talvez, justifique a denominação desse período, por parte das informantes, como "dieta". As práticas e os significados relativos à alimentação nesse período constituem o padrão cultural "Na 'dieta' os alimentos quentes são aconselháveis, e os ácidos, pesados e frios, não”, como pode ser observado nos excertos que seguem: 


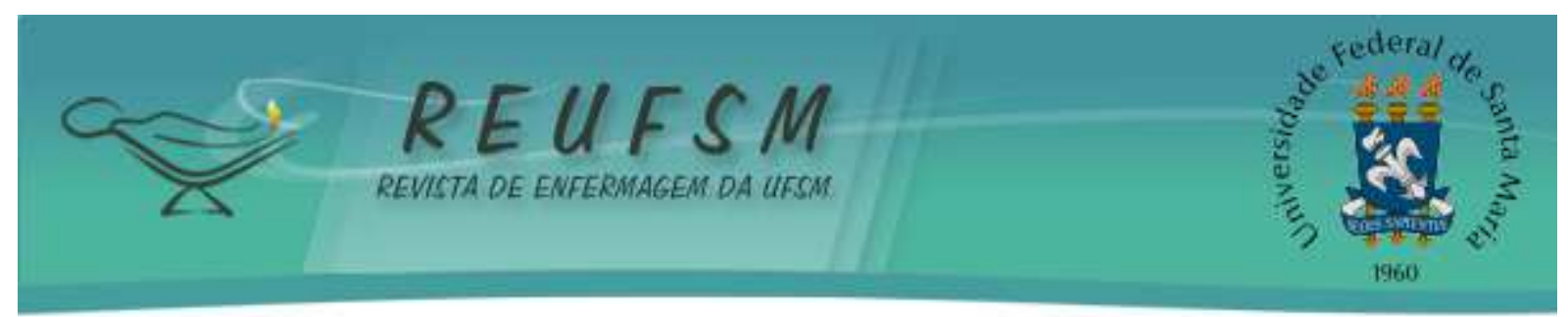

A minha sogra já dizia que, na dieta, tinha que comer só sopinha, que era leve. [...] E depois de 20 dias eu voltava a comer normalmente. (Informante-Chave, 61 anos, Vila Lorenzo)

Ganhei o nenê às nove da manhã e lá no hospital serviram, arroz, feijão, polenta e carne de galinha. Mas, em casa, por uns dez dias, na dieta, eu comi sopa. É, a gente cuida para ter uma comida leve, na dieta [complementa a sogra]. (Informante-chaves, 24 anos e 63 anos, Linha Santa Maria)

Entre os alimentos desaconselhados estão os classificados como pesados e/ou frios, dentre os quais são citados com frequência os que contêm acidez. Os hábitos alimentares, em si, sofrem variação de família para família, exceto o feijão, que não costuma ser consumido no puerpério. Contudo, alimentos como a mandioca, batata-doce, canjica, pinhão e carne de porco também foram mencionados, por algumas, como pesados. O chimarrão, bebida regional elaborada com a erva-mate (Illex paraguariensis), aparece entre os desaconselhados, possivelmente sendo classificado dentre os ácidos, visto que seu gosto amargo pode ser associado à acidez, além dos efeitos que consideram produzir sobre o lactente.

Eu não estou comendo coisas ácidas. Eu olho esses pés de laranja e de bergamota e morro de vontade de comer [risos]. Vinagre, salada também não. O feijão eu comi só uma vez e não comi mais. O que eu estou tomando é um chimarrãozinho, mas eu acho que vou ter que parar. As mais velhas dizem que o chimarrão dá cólica no nenê. (Informante-chave, 32 anos, Vila Lorenzo)

A médica disse que eu posso comer tudo. Só não exagerar. Já uns me dizem que vinagre, laranja, feijão, essas coisas fortes, que contêm ácido, eu não posso. Então, nos primeiros dias eu me cuidei, comi comida leve. O chimarrão eu não tomei ainda [35 dias de puerpério]. Dizem que dá cólica no nenê. (Informante-chave, 27 anos, Vila Lorenzo)

Essas restrições visam proteger indiretamente o recém-nascido, visto que as mulheres, além do conselho de outras mais experientes de seu grupo social, fazem associação entre as manifestações da criança, geralmente interpretadas como cólicas intestinais, e os alimentos ingeridos por elas. Entretanto, mesmo seguindo práticas de autoatenção, as quais comumente são geridas no âmbito da família, algumas vezes, em especial as nutrizes, procuram validar esses conhecimentos junto a profissionais do $\mathrm{MMH}$.

Na consulta da nenê, eu disse para o Dr. X: 'Doutor, e a alimentação, quanto a dar cólica? É verdade ou um pouco é mito? E ele disse, 'algumas coisas têm que se evitar. Mas tem que ir tenteando', ele 


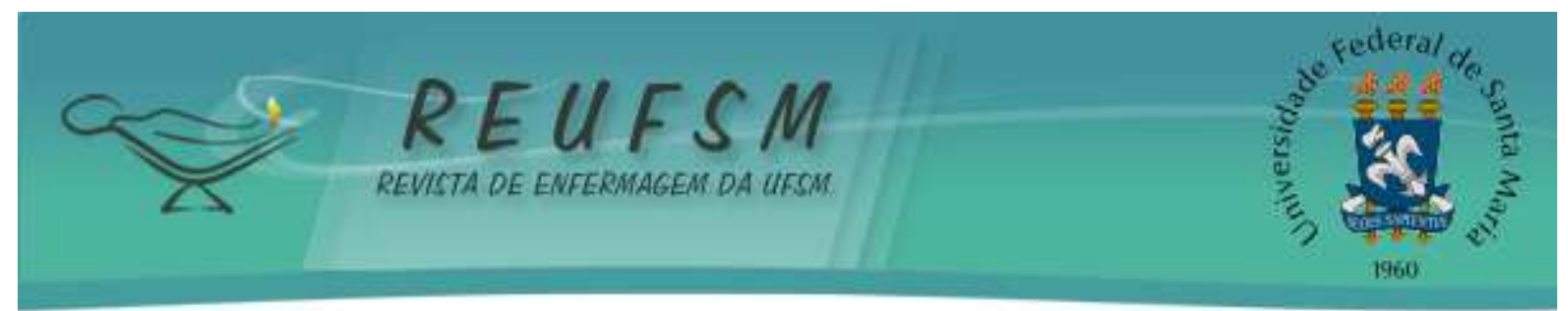

disse assim. Mas ele não me disse também que tipo de alimento que não pode dar. (Informante-chave, 32 anos, Vila Lorenzo)

Além disso, associam-se às práticas alimentares razões estéticas, salientando-se que essa referência foi feita pelas mulheres mais velhas do grupo, como se vê a seguir.

Se a mulher não se cuida na comida, que coma coisas pesadas, fica barriguda. A minha mãe dizia isso, são coisas que vêm lá da nossa avó. (Informante geral, 50 anos, Vila Lorenzo)

A mãe dizia que não podia comidas pesadas e frias - pinhão, mandioca, batata-doce, canjica, carne de porco, que era só de quinze dias em diante, pois a mulher ficava barriguda. E eu acredito porque nenhuma de nós [irmãs e tias] têm barriga. O meu avô era curandeiro, dava homeopatia e dizia: 'Minha filha, se cuide, porque a mulher que come comida gelada ou pesada ela fica barriguda'. Não que tivesse que ser quente, mas uma comida que é fria, uma comida pesada. $O$ intestino absorve aquelas comidas e a mulher está em convalescença, ela está 'doente', como diziam, e fica barriguda. Porque até na Bíblia diz que até o final da quarentena a mulher está impura e, então, eles cuidavam muito a gente. (Informante-chave, 75 anos, Vila Lorenzo)

Independentemente do tempo de observação dessas regras, é padrão na cultura estudada reiniciar gradativamente a ingesta dos alimentados proibidos, de forma que o organismo se readapte a eles.

Agora eu já estou comendo, mas pouquinho, e não sempre, lá de vez em quando. Na semana passada eu até comi feijão. Mas não todos os dias. Uma vez por semana. (Informante-chave, 27 anos, Vila Lorenzo)

No encontro etnográfico, observou-se que, nos primeiros 15 dias após o parto, as mulheres evitam sair de casa, a fim de se proteger das variações de temperatura ou da exposição ao vento, o que não significa, entretanto, que fiquem reclusas.

Nos primeiros quinze dias, como você vê, a gente fica mais dentro de casa. Para levar para vacinar, a gente se agasalha bem, para não pegar vento, friagem e para não expor ela também. Dizem que pode ter recaída. (Informante-chave, 27 anos, Vila Lorenzo)

Os cuidados com o frio e o calor referem-se também à exposição corporal à temperatura ambiente, do que emerge o segundo padrão cultural " $\mathrm{Na}$ 'dieta' a mulher não deve se expor a diferenças ambientais de temperatura". As práticas de autoatenção inerentes a esse padrão associam-se a cuidados com a cicatriz da cesariana. Assim, a mulher desvia-se do calor na região abdominal, evitando cozinhar nos primeiros dias após o parto. Além disso, 


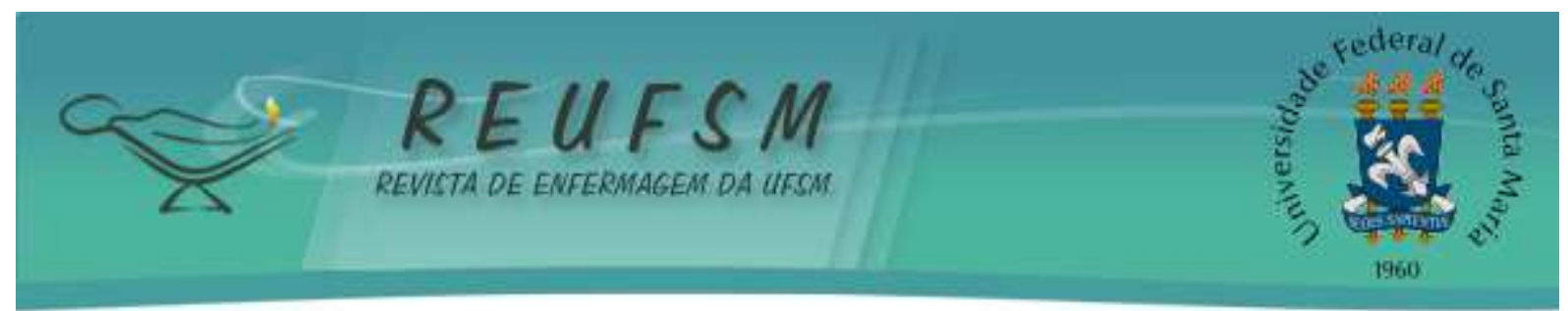

protege-se de mudanças bruscas de temperatura, afastando-se do frio da geladeira, por exemplo, quando está com o corpo quente.

Eu normalmente faço a minha comida, só que, agora, que diz que não pode ficar muito perto do fogo, da geladeira, quando estiver com o corpo quente, eu tô me cuidando. Peço almoço na minha sogra. (Informante-chave,27 anos, Vila Lorenzo)

O grupo se orienta, também, por regras relacionadas ao esforço físico nos primeiros dias após o parto, emergindo um terceiro padrão cultural: "Na 'dieta' a mulher não deve fazer esforço físico". Este padrão reforça a ideia do puerpério como um período de vulnerabilidade, pois a aptidão para o trabalho, nesta cultura, é interpretada como sinônimo de saúde. Assim, nesta etapa, as mulheres precisam se resguardar de atividades da vida diária que demandem esforço físico, dentre essas as laborais. Cabe a ressalva que o tempo de afastamento dessas atividades estará na dependência das condições socioeconômicas de cada família.

Não erguer muito peso, como a doutora me disse, que é para me cuidar até noventa dias. Então, eu só dou uma limpadinha na casa. A roupa, lavo na máquina. (Informantes-chave, 27 anos, Vila Lorenzo)

Nos primeiros dias eu tinha cuidado, porque eu ficava muito fraca mesmo. Mas em 15 dias já lavava roupa, mas não forcejava muito, fazia do jeito que a mãe ensinava. Lustrar a casa, não fazia exagero. Ela dizia que era para não ficar barriguda. Eu não sei se é mesmo, mas era o que ela dizia. (Informante-chave, 61 anos, Vila Lorenzo)

No conjunto de práticas que visam proteger a mulher de esforços no puerpério, surgiu a restrição à leitura. Isto foi enunciado uma única vez pela informante-chave mais idosa da investigação, na ocasião em que foi entregue o Termo de Consentimento Livre e Esclarecido para uma das puérperas, solicitando-se que o lesse até o dia seguinte, quando a pesquisadora voltaria ao domicílio a fim de verificar se iria ou não compor o grupo de pesquisa.

E daí tu pode pedir pro José [o esposo] ler para você, se tu não quiseres ler [interpela a informante]. [Em casa, eu pergunto: Por que a senhora pediu que o José lesse para ela?] Porque as vistas ficam meio fracas depois que a gente ganha nenê e tem gente que acha não é bom ler, porque prejudica as vistas. (Diário de campo, Informante-chave, 75 anos, Vila Lorenzo)

À semelhança das experiências em relação à ingestão de alimentos, o tempo de observação das restrições relativas à atividade física varia entre as mulheres do grupo, inclusive no interior de uma mesma geração. A observância desse tempo parece guardar relação, dentre outras razões, com as condições econômico-financeiras de cada mulher e de 


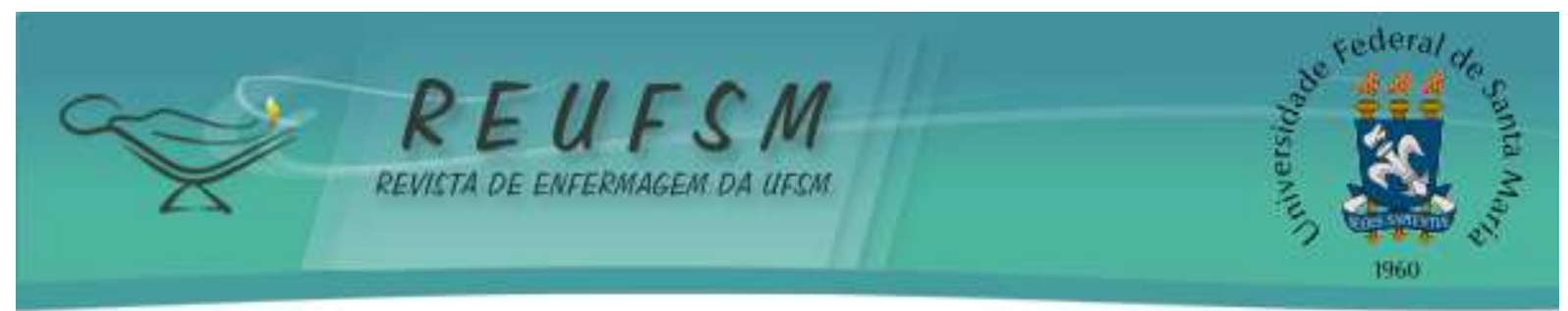

seu grupo social, o que, para umas, exigirá o retorno às atividades cotidianas bem antes do que para outras, como pode ser observado na seguinte fala:

Em uns três dias depois do parto eu já fazia todo o serviço da casa, logo depois eu já tava fazendo o serviço da casa, lavando roupa. (Informante-chave, 69 anos, Vila Lorenzo)

Foram observados alguns cuidados em relação à higiene corporal, porém restritos à lavagem dos cabelos, configurando em mais um padrão cultural do grupo em estudo: " $\mathrm{Na}$ ‘dieta' a mulher deve ter cuidados em relação à lavagem do cabelo”. Interessa notar que algumas mulheres, mesmo lavando o cabelo durante o período menstrual, por exemplo, suspendem esse hábito no puerpério e, guiadas pela orientação de outras mais experientes, consideram sensato tomar alguns cuidados em relação a essa prática.

A minha mãe recomendava esperar uns 45 dias para lavar o cabelo. Esperei dez. Eu disse, vou esperar até quando aguentar. A mãe aguentou os 40 dias, [comenta a puérpera. Sua irmã complementa]: Porque podia dar dor de cabeça, uma recaída, e daí ela fazia medo para gente. [A puérpera continua]: A minha cunhada disse que eu podia lavar, porque o dia que ela chegou em casa ela lavou a cabeça. Mas eu fiquei naquela da mãe [risos]. Esperei uns dias. (Informanteschave, 27 e 22 anos, Vila Lorenzo)

Ainda, com base na percepção da vulnerabilidade da mulher no puerpério, e em razão dos significados sociais e afetivos relacionados à chegada de um bebê na comunidade, observou-se que a família se mobiliza para dar apoio à puérpera. Em especial na primeira semana, é costume uma mulher, geralmente da linhagem da puérpera, mudar-se para a casa do casal para auxiliar nas tarefas domésticas. Quando já não contam com essa ajuda, a sogra tomará para si algumas tarefas domésticas, visto que, comumente, ela mora em frente ou ao lado da residência do casal, em razão da conformação quase sempre patrilinear das famílias desta investigação. Esta prática constitui o último padrão cultural que compõe este tema cultural: "Os familiares e a comunidade se mobilizam para ajudar e acolher a puérpera na 'dieta'”.

Nos dez primeiros dias eu me mudei para a casa deles para ajudar no serviço e com a nenê. (Informantes-chave, 24 e 63 anos, Linha Santa Maria)

Chegando à residência de pretensa informante do estudo, o pai da criança se adianta e diz que a esposa está repousando e que aquela moça com o bebê ao colo é cunhada de sua esposa e que está ali ajudando nos primeiros dias. [...] Durante uma tarde, ouço um ruído e 


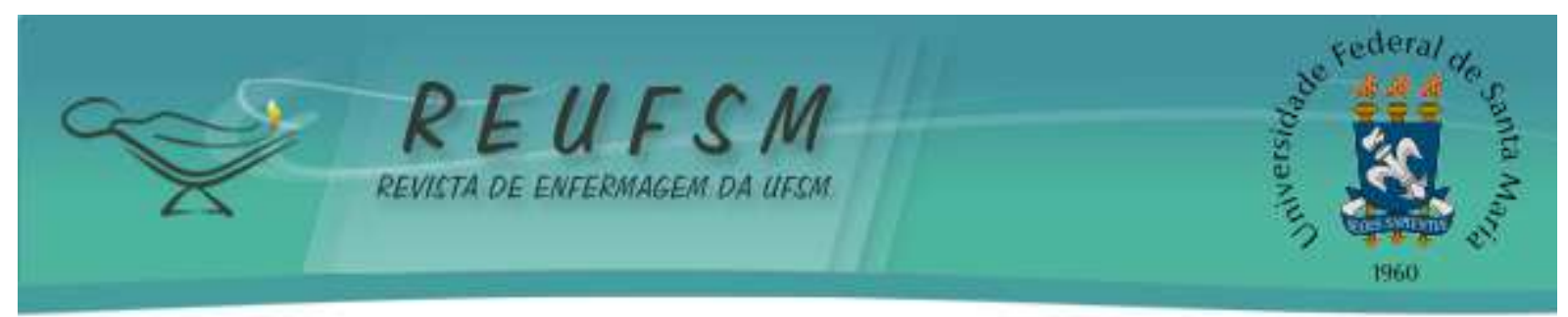

pergunto à puérpera acerca do barulho, ao que diz que deve ser sua sogra recolhendo a roupa do varal. 'Ela tem me ajudado muito, porque ela acha que eu não posso sair para recolher a roupa. Ela é uma mãe para mim'. (Diário de campo, Informante-chave, 32 anos, Vila Lorenzo)

Destaca-se, no cenário focalizado, o hábito da realização de visita à puérpera quando da sua volta para casa, após o parto. Nessa ocasião, a criança receberá um "mimo" confeccionado pela própria visitante ou algo que foi comprado especialmente para o bebê.

Observo que, ao final da visita, ao se despedirem da puérpera, cada uma das senhoras entrega um pacotinho à dona da casa. Em um deles há um sapatinho tricotado em lã vermelha e no outro um babeiro bordado à mão. Pergunto se foram elas que confeccionaram ao que me respondem que sim. (Diário de campo, Informante-chave, 27 anos, Vila Lorenzo)

\section{DISCUSSÃO}

Os dados revelam que a alimentação é alvo de diversas práticas de autoatenção, as quais buscam, dentre outros objetivos, garantir o funcionamento adequado do organismo humano. Estas são informadas, especialmente, pelo princípio do equilíbrio entre o frio e o quente, elementos constituintes da teoria humoral hipocrática, que já foi hegemônica em tempos de um Brasil eminentemente rural. ${ }^{16}$

No interior de um sistema de crenças e regras, os alimentos são categorizados, pelo grupo de informantes, em quentes e frios, leves e pesados. O período da "dieta", a inferir-se do conteúdo simbólico das narrativas, classifica-se como frio, possivelmente em decorrência da perda de sangue, identificado como quente, que ocorre no parto. A partir dessa lógica emergem algumas práticas alimentares, que parecem ter como objetivo fornecer calor à puérpera na busca de equilíbrio do organismo. Por isso, nos primeiros dias após o parto, em casa, é oferecido à mulher um "caldinho quente". Aliado a isso, a sopa emerge como símbolo do laço social que se fortalece no drama do nascimento, visto que há uma mobilização para o preparo e a oferta desse alimento, tanto no pré-parto como no puerpério.

No que diz respeito à recomendação temporal das restrições alimentares, ela se assemelha a de outras realidades culturais, inclusive urbanas, ${ }^{4,17}$ variando de acordo com os costumes das famílias e correspondendo a um período que não é menor que sete dias e não chega aos quarenta. Esse será um tempo que a família, geralmente ancorada nos 


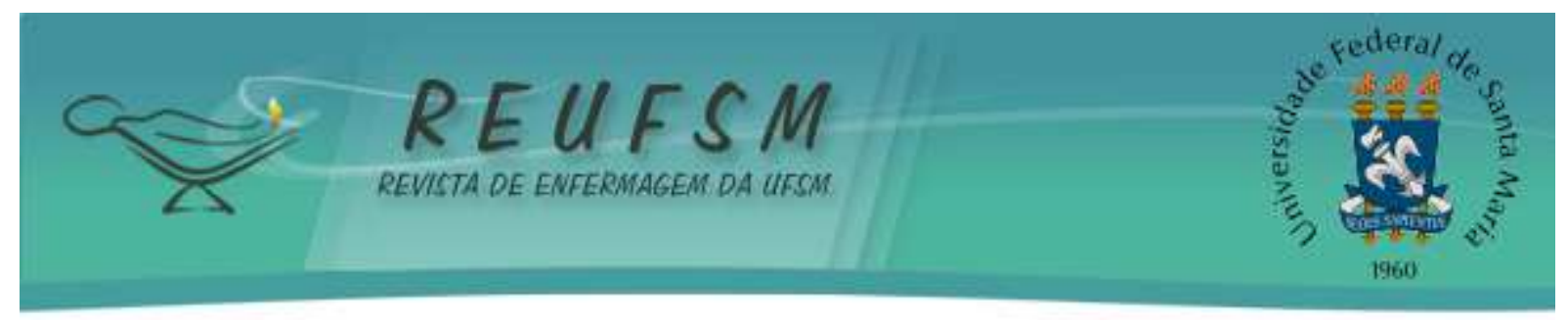

conhecimentos que circulam no seu grupo social, entende ser necessário para proteger a mulher, visto que interpretam que, na "dieta", ela estará entre a saúde e a doença. Tal interpretação, de certa forma, anuncia a representação social do feminino no cenário estudado, em que a "impureza" pode representar ameaça a si mesma, ao filho e ao grupo. ${ }^{16}$ Em algumas cenas observadas, inclusive no cenário geral da investigação, mulheres mencionaram que as parturientes e as puérperas eram consideradas "doentes" pelas pessoas mais velhas do grupo.

Nessa perspectiva, a ingesta gradativa de alimentos interditados durante a "dieta" simboliza o afastamento da mulher da condição de "doente" e seu reencontro paulatino com o estado de "saúde", o que a habilitará para o "reingresso" no seu grupo e cumprimento do papel social materno no fechamento de um ciclo e início de outro.

Norteado também pelo princípio do frio e do quente e, possivelmente, pela noção de que o corpo se abre no parto, fechando-se somente ao final do puerpério, o que o deixa vulnerável, ${ }^{3-4}$ emergiu, de forma semelhante a estudo realizado no litoral sul do $\mathrm{RS}^{4}$ e entre campesinas gaúchas ${ }^{18}$ o segundo padrão cultural "Na 'dieta' a mulher não deve fazer esforço físico".

As práticas de autoatenção neste padrão são, quase sempre, inerentes às atividades laborais das mulheres do meio rural e provêm da articulação de saberes familiares/comunitários com os do $\mathrm{MMH}$, com evidentes ressignificações que culminam na formulação de modelos explanatórios próprios. ${ }^{6,10}$ Esta formulação se dá, em geral, porque as orientações do MMH são bastante genéricas, não especificando quais alimentos ou atividades são permitidos ou não nesta fase da vida, exigindo a produção de tais modelos.

Disso, percebe-se a pertinência de que o enfermeiro, na atenção às puérperas residentes no meio rural, volte-se, para além dos aspectos biológicos, às questões sociais e estruturais referentes a essa mulher e ao seu grupo social para que, em diálogo intercultural e em corresponsabilidade, busquem formas de garantir a promoção da saúde. ${ }^{19}$

Quanto às restrições relativas à lavagem dos cabelos no puerpério, comuns em diferentes culturas, ${ }^{4,16}$ apreende-se que esta é uma prática de autoatenção que, no cenário em estudo, sofreu modificações ao longo do tempo. Estas ocorreram em razão do contato das informantes com os saberes do MMH, mas, apesar de transformada, ela se constitui em um padrão cultural que rege seus saberes e fazeres no pós-parto. A noção de "recaída" (complicações decorrentes de práticas inadequadas no puerpério) orienta essa prática de 


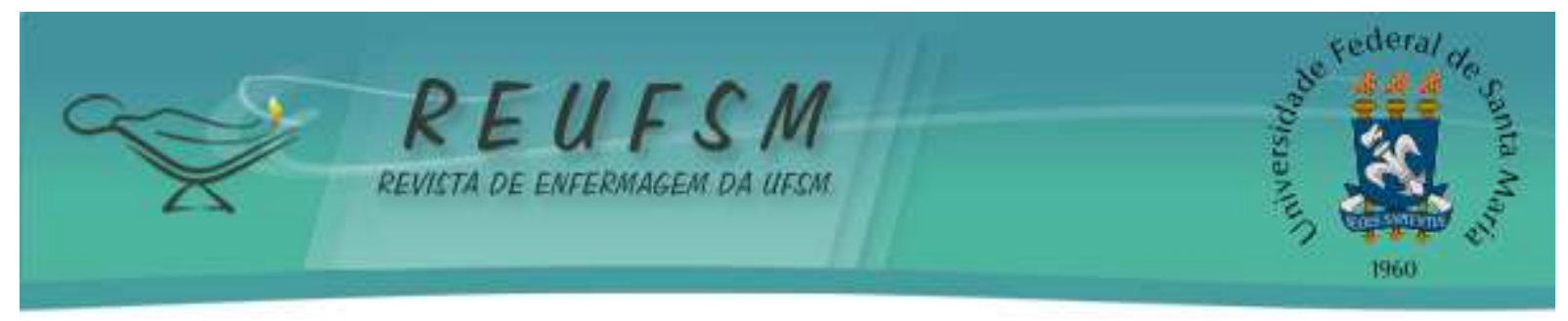

autoatenção. Entretanto, destaca-se que essa não aparece de forma explícita nas narrativas como algo do campo da saúde mental, a exemplo de resultados de estudo do litoral gaúcho. ${ }^{4}$ No entanto, o descumprimento dessa regra é associado à possibilidade de cefaleia, cabendo lembrar que a cabeça é a parte do corpo popularmente associada a distúrbios mentais.

Os achados revelam que as práticas de autoatenção produzidas na "dieta" vão tomando contornos diferenciados a depender do acervo de conhecimentos da família e do contexto em que vivem. Enquanto que, em algumas famílias, a preocupação com o frio e o calor, por exemplo, refere-se à manutenção do equilíbrio do organismo humano, para outras terá, também, relação com a estética corporal. Algumas, por sua vez, consideram que interferências na estética serão controladas exclusivamente por meio da alimentação, outras acreditam que se associam com o esforço físico, que deve ser evitado no puerpério.

Contudo, apesar dessas diferenças, as finalidades explícitas das práticas de autoatenção serão a proteção à mulher e à criança, a promoção da saúde e a prevenção de agravos, o que valida o pensamento de que todo o padecimento implica, necessariamente, a existência de formas de atenção e de prevenção, ${ }^{6}$ cujo reconhecimento, por parte dos profissionais de saúde, incluídos os enfermeiros, parece ser fundamental para a produção de cuidados culturalmente congruentes que atendam as expectativas de quem busca o MMH.

O último padrão cultural, "Os familiares e a comunidade se mobilizam para ajudar e acolher a puérpera na 'dieta'”, reitera que as práticas de autoatenção produzidas no puerpério pelo grupo em estudo são semelhantes às de outros grupos culturais, inclusive urbanos, ${ }^{4}$ motivado, talvez, pela imprecisão das fronteiras entre rural e urbano, tendência de um mundo globalizado. Entretanto, não deixa de chamar atenção o desenvolvimento de práticas de sociabilidade quando da chegada de um recém-nascido ao cenário focalizado, a exemplo da visita à família e do hábito de presentear o bebê. Infere-se, dessas práticas, que o PN para o grupo estudado terá sentido e significado mais intenso a partir do período puerperal, quando a presença da criança materializa e dá concretude ao nascimento.

As práticas de autoatenção produzidas no puerpério pelas mulheres rurais e seus grupos sociais constituem uma urdidura, cujos fios da trama são mais exclusivos à família e à comunidade dessa que se torna mãe. Desse modo, sua tessitura se ancora em significados relacionados à própria puérpera, ao puerpério, à maternidade e à criança, nos seus aspectos concretos e simbólicos. Assim, no puerpério, as mulheres do meio rural se afastam um pouco 


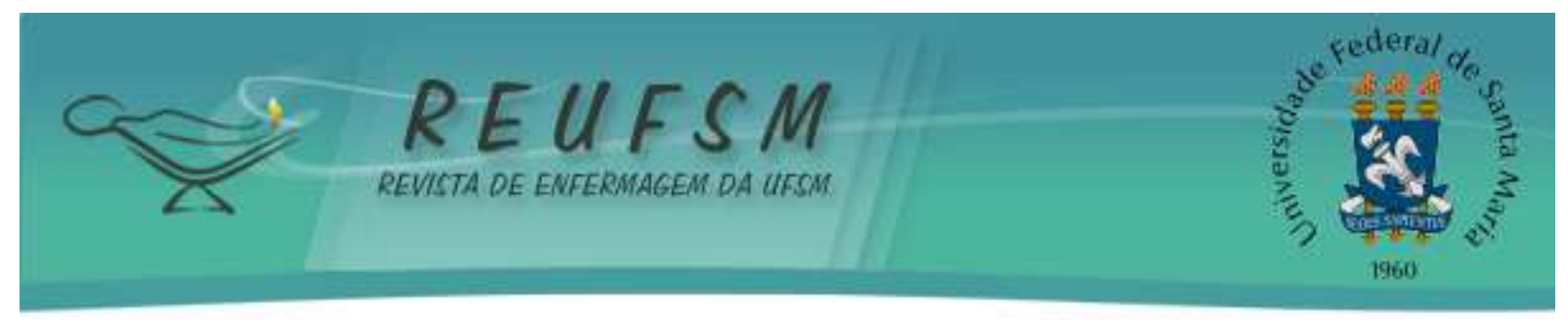

do controle higienista representado pela biomedicina (paradigma que ancora o MMH) e, por isso, produzem determinada autonomia em suas práticas e seus modelos explanatórios. Contudo, pelo fato de se inserirem em determinada sociedade que, por sua vez, está envolta em uma rede de símbolos e de significados tecida por si mesmas, por suas famílias e pelas demais pessoas da comunidade em que convivem, essa será sempre uma autonomia relativa. ${ }^{10}$

Desde essa perspectiva, tem-se como tese que as práticas de autoatenção produzidas no puerpério pelas mulheres do campo passam pela mediação cultural. Elas se relacionam com formas simbólicas compartilhadas pelo grupo social a que pertencem essas mulheres, as quais são produtoras de sentidos e de significações que contribuem para modelar essas mesmas práticas. Assim, o reconhecimento por parte dos profissionais de saúde, dentre esses os enfermeiros, acerca desses sentidos e significados, e da intencionalidade que deles é gerada, parece importante para a produção de cuidados culturalmente congruentes, o que demanda habilidade e competência para operar interpretações fundamentadas no relativismo cultural. Para isso, desde o curso de graduação, conhecimentos culturais necessitam compor a transversalidade do processo formativo, de modo que eles não representem apenas mais uma disciplina isolada, cujo sentido geralmente é inacessível aos estudantes.

\section{CONSIDERAÇÕES FINAIS}

Do encontro etnográfico emerge que as práticas de autoatenção no puerpério, denominado "dieta" no cenário investigado, se referem aos hábitos alimentares, à atividade física e laboral, à higiene corporal e a atos de solidariedade e de sociabilidade, que objetivam a proteção da mulher, a qual está em um estado liminar nesse momento - entre a saúde e a doença. Indiretamente buscam, também, proteger a criança e seu grupo social.

Acredita-se que este estudo possa contribuir no campo da saúde, em especial da enfermagem, porque a interpretação de conhecimentos culturais específicos pode ancorar estratégias para a melhoria das condições de saúde das populações, no que se incluem as mulheres-puérperas residentes no meio rural. O esgarçamento da trama vivida por essas mulheres poderá contribuir para que profissionais reflitam sobre os tensionamentos existentes entre os distintos modelos de atenção em que elas e suas famílias circulam, no intuito de compor suas práticas de autoatenção e, a partir daí, examinem quais dispositivos podem manejar, a fim de chegar à negociação cultural em suas realidades específicas. 


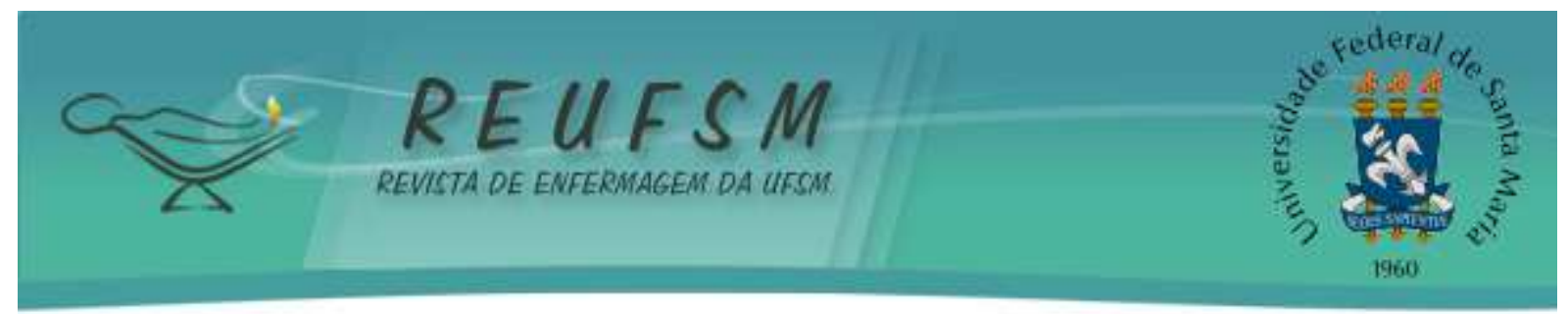

Considerando-se que todas as autoras são docentes de enfermagem, cabe assinalar que o empreendimento etnográfico aponta para a importância de, em "sala de aula", estimular, desde o início do processo de formação, o exercício dos três atos cognitivos que fundam a produção do conhecimento: o olhar, o ouvir e o escrever. Por meio desses três atos, o estudante terá elementos para consolidar sua capacidade de interpretação e de reflexão crítica sobre as motivações simbólicas e as determinações políticas e sociais que orientam os sujeitos e seus conjuntos sociais na tomada de decisões em relação às suas práticas de autoatenção.

Com isso, o futuro profissional fortalecerá sua habilidade e sua competência para o exercício do atributo da empatia, entendida como a capacidade de colocar-se no "lugar" do outro, em uma tentativa de ver o mundo pela lente desse outro, sem ser o outro. Essa habilidade concorrerá para que ele se disponha à negociação cultural, contribuindo na produção de saúde que considere e respeite os modos de viver das mulheres do campo e, em consequência, suas práticas de autoatenção naquilo que têm de concreto e de simbólico.

O fato de os profissionais de saúde do cenário focalizado deste estudo, vinculados ao $\mathrm{MMH}$, terem sido somente observados e não entrevistados, representa uma das limitações da investigação. Isto sinaliza a possibilidade de novas pesquisas que os incluam em entrevistas, podendo contribuir na interpretação das tensões e das disputas existentes entre os diferentes modelos de atenção e de autoatenção no puerpério, ampliando o olhar sobre os dados.

\section{REFERÊNCIAS}

1. Maldonado MT. Psicologia da gravidez. Rio de Janeiro (RJ): Jaguatirica; 2013.

2. Rezende J, Montenegro CAB. Obstetrícia fundamental. $13^{\mathrm{a}}$ ed. Rio de Janeiro (RJ): Guanabara Koogan; 2014.

3. Santos FAPS, Brito RS, Mazzo MHSN. Puerpério e revisão pós-parto : significados atribuídos pela puérpera. REME Rev Min Enferm [Internet]. 2013 out-dez [acesso em 2014 jan 03];17(4):854-8. Disponível em: http://www.reme.org.br/artigo/detalhes/891.

4. Acosta DF, Gomes VLO, Kerber NPC, Costa CFS. Influências, crenças e práticas no autocuidado das puérperas. Rev Esc Enferm USP [Internet]. 2012 [acesso em 2013 ago 01];46(6):1327-33. Disponível em: http://www.scielo.br/pdf/reeusp/v46n6/07.pdf.

5. Geertz C. A interpretação das culturas [e-book]. Rio de Janeiro (RJ): LTC; 2015. Uma descrição densa. p. 3-21.

6. Menéndez EL. Modelos de atención de los padecimientos : de exclusiones teóricas y articulaciones prácticas. Ciênc Saúde Colet [Internet]. 2003 [acesso em 2013 maio 02]; 8(1):185-207. Disponível em: http://www.scielo.br/pdf/csc/v8n1/a14v08n1.pdf. 


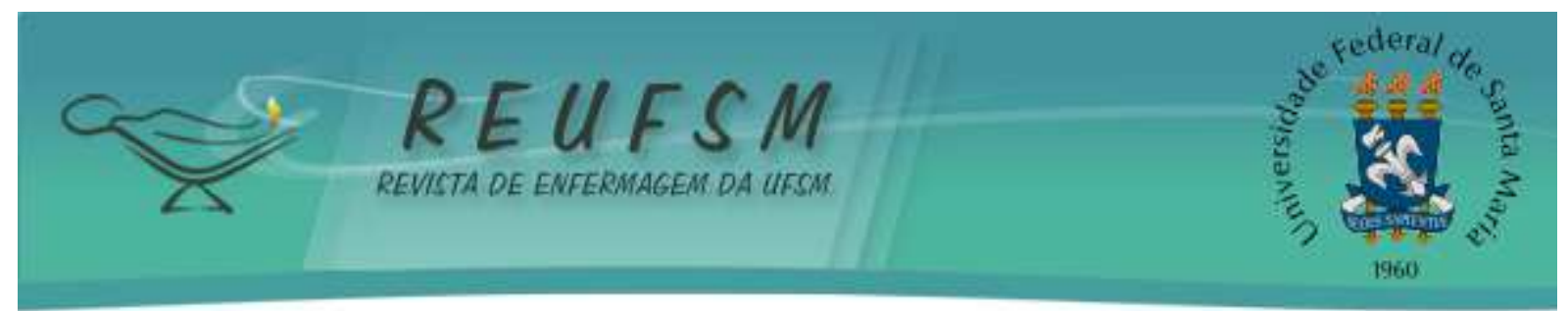

7. Deeb-Sossa N, Olavarrieta CD, Juárez-Ramírez C, García SG., Villalobos A. Experiencias de mujeres mexicanas migrantes indocumentadas en California, Estados Unidos, en su acceso a los servicios de salud sexual y reproductiva: estudio de caso. Cad Saúde Pública [Internet]. 2013 maio [acesso em 2018 fev 06];29(5):981-91. Disponível em: http://www.scielo.br/pdf/csp/v29n5/15.pdf.

8. Qureshi R, Pacquiao DF. Ethnographic study of experiences of pakistani women immigrants with pregnancy, birthing, and postpartum care in the United States and Pakistan. J Transcult Nurs [Internet]. 2013 out [acesso em 2017 fev 04];24(4):355-62. Disponível em: https://www.ncbi.nlm.nih.gov/pubmed/23835891.

9. Yajahuanca RSA. A experiência de gravidez, parto e pós-parto das imigrantes bolivianas e seus desencontros na cidade de São Paulo - Brasil [tese]. São Paulo: Universidade de São Paulo, Faculdade de Saúde Pública; 2015. 192p.

10. Menéndez EL. Entrevista: Eduardo Luis Menéndez Spina. Trab Educ Saúde [Internet]. 2012 jul-out [acesso em 2013 maio 02];10(2):335-45. Disponível em: http://www.scielo.br/pdf/tes/v10n2/09.pdf.

11. Instituto Brasileiro de Geografia e Estatística. Rio Grande do Sul [Internet]. 2013 [acesso em 2017 fev 02]. Disponível em: https://cidades.ibge.gov.br/brasil/rs/panorama.

12. Leininger M, McFarland M. Culture and diversity: a worldwide nursing theory. 2nd ed. Boston (US): Jones and Bartlett Publishers; 2006.

13. Outwater AH, Tarimo EA, Miller JE, Campbell JC. Meanings of care by bereaved relatives of homicide victims in Dar es Salaam, Tanzania: implications for nursing. J Transcult Nurs [Internet]. 2012 out [acesso em 2017 fev 06];23(4):397-405. Disponível em: https://www.ncbi.nlm.nih.gov/pubmed/22802300.

14. Brasil. Ministério da Saúde. Conselho Nacional de Saúde. Resolução n. 196, de 10 de outubro de 1996. Diretrizes e normas regulamentadoras de pesquisa envolvendo seres humanos. Brasília (DF): Ministério da Saúde; 1996.

15. Kleinman A. Patients and healers in the context of culture: an exploration of the borderland between Anthropology, Medicine and Psychiatry. Berkeley, Los Angeles, London: University of California Press; 1980. Orientation 2: culture, health care systems and clinical reality. p. 24-70.

16. Helman C. Culture, health and ilness: an introduction for health professionals [e-book]. 2nd ed. Grã-Bretanha: Butterworth; 2014.

17. Baião MR, Santos MMAS, Líbera BD, Machado RCMM. O puerpério e sua dimensão sociocultural na perspectiva de mulheres moradoras da região de Manguinhos - Rio de Janeiro, RJ. Demetra [Internet]. 2013 [acesso em 2017 fev 04];8 Supl 1:309-20. Disponível em: http://www.e-publicacoes.uerj.br/index.php/demetra/article/view/6562/5675.

18. Vargas NSC, Ceolin T, Casarin ST, Mendieta MC, Lopes CV, Piriz MA. Práticas de cuidado à saúde realizadas no período puerperal por agricultoras. Rev Enferm UFSM [Internet]. 2017 [acesso em 2018 jun 01];7(2):304-13. Disponível em: https://periodicos.ufsm.br/reufsm/article/view/24122/pdf. 


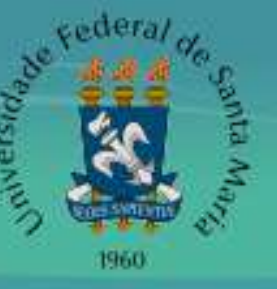

19. Prigol AP, Baruffi LM. O papel do enfermeiro no cuidado à puérpera. Rev Enferm UFSM [Internet]. 2017 [acesso em 2017 ago 04];7(1):1-8. Disponível em: https://periodicos.ufsm.br/reufsm/article/view/22286/pdf.

Data de submissão: 10/01/2018

Data de aceite: $17 / 10 / 2018$

Autor correspondente: Isabel Cristina Pacheco van der Sand

E-mail: isabelvan@gmail.com

Endereço: Rua Ângelo Strapazon, 310, Centro, Ijuí/RS, Brasil.

CEP: 98700-000 